\title{
Sugar-sweetened beverage affordability and the prevalence of overweight and obesity in a cross section of countries
}

\author{
Fabrizio Ferretti ${ }^{*}$ (D) and Michele Mariani
}

\begin{abstract}
Background: A key component of 'obesogenic environments' is the ready availability of convenient, calorie-dense foods, in the form of hyper-palatable and relatively inexpensive ultra-processed products. Compelling evidence indicates that the regular consumption of soft drinks, specifically carbonated and non-carbonated sugar-sweetened beverages (SSBs), has a significant impact on the prevalence of overweight and obesity. However, to implement country-level effective prevention programmes we need to supplement this evidence with quantitative knowledge of the relationships between overweight/obesity and the main determinants of SSB consumption, notably SSB prices and consumers' disposable income.
\end{abstract}

Method: Affordability considers the simultaneous effects of both price and disposable income on the buying decision. The purpose of this study was to investigate the effect of SSB affordability on the consumers' purchasing behaviour and weight-related health outcomes. Our study was divided into three parts. First, we computed SSB consumption and affordability for approximately 150 countries worldwide. Second, we estimated a demand function for SSBs to assess the impact of affordability on consumption at the country level. Third, we used a multivariate regression model and country data on the prevalence of overweight and obesity to test the role of SSB affordability in the current obesity epidemic.

Results: The analysis reveals that SSB affordability: 1) showed both a large variability across countries and a clear tendency to increase substantially with the level of economic development; 2) played a key role in determining cross-country differences in the amount of soft drink consumed per capita; and 3) was significantly associated with the prevalence rates of both overweight and obesity. Specifically, we show that a $10 \%$ increase in SSB affordability was associated, on average, with approximately 0.4 more overweight/obese adults per 100 inhabitants.

Conclusions: By controlling for the main possible confounding factors, our results clearly indicate that affordability is a major driver of purchasing behaviours and is significantly associated with the prevalence rates of both overweight and obesity. We thus suggest a fiscal approach to curb SSB consumption based on the effectiveness of 'soda taxes' to affect the long-term dynamic of SSB affordability.

Keywords: Affordability, Globalization, Obesity, Overweight, Soft drinks, Sugar-sweetened beverages

\footnotetext{
* Correspondence: fabrizio.ferretti@unimore.it

School of Social Sciences, Department of Communication and Economics,

University of Modena and Reggio Emilia, Palazzo Dossetti, Viale Allegri, 9,

42121 Reggio Emilia, Italy
}

(c) The Author(s). 2019 Open Access This article is distributed under the terms of the Creative Commons Attribution 4.0 International License (http://creativecommons.org/licenses/by/4.0/), which permits unrestricted use, distribution, and reproduction in any medium, provided you give appropriate credit to the original author(s) and the source, provide a link to the Creative Commons license, and indicate if changes were made. The Creative Commons Public Domain Dedication waiver (http://creativecommons.org/publicdomain/zero/1.0/) applies to the data made available in this article, unless otherwise stated. 


\section{Background}

Overweight and obesity are usually defined as an abnormal or excessive body fat accumulation that might seriously impair people's health [1]. Overweight and obesity are indeed major risk factors for many severe non-communicable diseases, such as cardiovascular diseases, diabetes, musculoskeletal disorders, and also some types of cancers [2].

It is widely acknowledged that, although they are complex and multifactorial conditions, overweight and obesity would be largely preventable through 'relatively simple' lifestyle changes $[3,4]$. Despite this, the worldwide prevalence of overweight and obesity has increased substantially during the last decades [5]. Nowadays, it is estimated that approximately two-thirds of the world's population lives in countries where there are more deaths attributable to overweight and obesity-related diseases than to underweight and malnutrition [6]. If recent trends continue unchanged, the latest projections suggest that by 2030 up to $57.8 \%$ of the world's adult population could be either overweight or obese [7].

An abnormal or excessive body fat accumulation results from a sustained positive energy imbalance between calories consumed and calories expended [8]. Besides the role of heredity, this energy imbalance comes from the adoption of lifestyles characterized by an unhealthy diet and/or a lack of physical activity [9]. Research has shown that the spread of overweight and obesity in high- and middle-income countries is mainly driven by structural changes that affect these health-related habits and behaviours [10].

In particular, in many countries the intensive use of sophisticated food processing technologies, aggressive food marketing strategies, and the pervasive diffusion of ICT technologies and automation (along with urbanization, aging, and other cultural, economic, and social transformations), have developed into an 'obesogenic environment' $[11,12]$, that is a society that tends to promote unhealthy weight gain by pushing people towards overweight and obesity-prone lifestyles [13].

A key component of these 'obesogenic environments' is the high availability of convenient (i.e. durable and ready to consume), calorie-dense foods in the form of hyperpalatable and relatively inexpensive, ultra-processed products $[14,15]$. These foods are typically low in nutrients and high in added fat and sugars, and their daily consumption is strongly associated with a higher risk of becoming overweight or obese $[16,17]$.

In addition to ultra-processed foods, an important source of 'empty calories' are soft drinks-specifically carbonated and non-carbonated sugar-sweetened beverages (SSBs), such as sodas and ready-to-drink tea, fruit and fruit flavored beverages - that usually contain large amounts of refined sugars (most often high-fructose corn syrup) but few or no nutrients ${ }^{1}[18,19]$.

The worldwide demand for these beverages has grown rapidly over the last decades [20,21]. Despite some recent signs of a trend reversal in North American and European countries (especially for non-diet carbonated soft drinks), the per capita consumption of SSBs still remains high in both middle- and high-income countries and is predicted to rise in the near future, especially in populous and fast-growing economies such as China and India [22].

Compelling evidence from observational studies and experimental trials indicates that the regular consumption of SSBs has a significant impact on the prevalence of overweight and obesity (in both children and adults) and contributes substantially to the onset of other metabolic diseases (notably, type 2 diabetes) [23-25]. To implement country-level effective overweight and obesity prevention programmes, however, this evidence should be supplemented with thorough quantitative knowledge of the relationships between overweight/obesity and the main determinants of SSB consumption, notably SSB prices and consumer disposable income [26, 27].

So far a lack of reliable and comparable country data on both overweight and obesity prevalence and SSB sales and prices has limited the application of ecological studies to this public health issue. More recently, however, by taking advantage of new cross-country data sets, some studies have found that carbonated soft drink consumption is significantly linked to overweight and obesity worldwide [28], whereas others have restricted this link to low- and middle-income countries and have also found little or no robust evidence of the effects of soft drink prices on unhealthy weight gain indicators [29].

These mixed results suggest the need for further research. In the pages that follow, we build on such previous studies to fill a specific research gap in the existing literature. Among the open questions, there is a lack of knowledge about the role of SSB affordability on consumers' purchasing behaviour and weight-related health outcomes [30].

Broadly speaking, affordability considers the simultaneous effects of both price and disposable income on a consumer's buying decision and thus captures the consumer's 'ability to purchase a specific good or service [31]. The concept of affordability is commonly used to investigate the demand for other important health-related goods, such as alcohol and tobacco [32, 33].

In a nutshell, the rest of this paper represents an attempt to answer a single and high-impact research question: does SSB affordability affect overweight and obesity prevalence worldwide? To answer this, we proceeded in three steps. First, we used the latest statistics available on the beverage market to compute the per capita consumption and comparable measures of SSB prices and affordability for a large number of countries (approximately 150 countries, from all world regions, and with different levels of economic development). Next, we estimated a demand function for SSBs to investigate the impact of affordability on consumption at the country 
level. Finally, we compared country data on SSB consumption and affordability with data on the prevalence of overweight and obesity to test whether the affordability of SSBs should be included among the key drivers of the so-called 'obesity pandemic'.

\section{Data}

The data utilised in this study were obtained from six main sources: Euromonitor International, the World Health Organization (WHO), the United Nations' Food and Agriculture Organization (FAO) and Human Development Report (HDR), the World Bank, and the Swiss Economic Institute (Konjunkturforschungsstelle, KOF).

Euromonitor International regularly updates a comprehensive database on the beverage industry [34]. This database contains information on soft drink sales, in both volume and value, for a large number of countries worldwide. Using these data, we first computed the per capita annual consumption of SSBs $(Q)$ in each country by dividing the total sales in volume of non-carbonated (i.e. ready-to-drink tea, coffee, and juices, as well as sports/energy and Asian drinks ${ }^{2}$ ) and carbonated soft drinks by the total country population. $Q$ includes on-trade and off-trade sales of both domestically manufactured and imported beverages. Population data were taken from the United Nations HDR database [35].

Second, we obtained an average market price of SSBs $(P)$ at the country level by dividing total sales in value by total sales in volume. These average annual prices, expressed in local currency, were converted to a common currency using purchasing power parity (PPP) conversion factors from the World Bank's International Comparison Program database [36]. In a similar way, using Euromonitor data, we computed the average annual price and per capita consumption of bottled (still and carbonated) water, respectively denoted as $P W$ and $Q W$ [34].

Within the Global Health Observatory, the WHO provides comparable estimates of the prevalence of overweight and obesity for almost all countries worldwide [37]. From this data repository, we retrieved the age-standardized adjusted estimates of the prevalence of overweight $(P O W)$ and obesity $(P O B)$ among the adult population. $P O W$ and $P O B$ are measured by the percentage of adults (aged 18+ years) who have a body mass index (BMI) equal to or greater than $25 \mathrm{~kg} / \mathrm{m}^{2}$ or $30 \mathrm{~kg} / \mathrm{m}^{2}$, respectively (where BMI is defined as weight in kilograms divided by the square of height in meters).

To isolate the impact of SSB consumption and affordability on population-wide unhealthy weight gains, we included in our database a number of control variables that previous research has linked to the spread of overweight and obesity. Increased food energy supply has been proven to be a key driver of the obesity epidemic [38]. Dietary energy supply (DES, expressed in kcal/ person/day) is a common measure of the average amount of the food available for human consumption at the country level. We used internationally comparable $D E S$ estimates, as computed by the FAO from national balance food sheets [39].

Urbanization and economic structural changes affect people's health-related habits and behaviours, influencing the prevalence of overweight and obesity [40]. We tried to capture the impact of these factors by including the percentage of the total population that lives in urban areas $(U R B)$, as well as the percentage of total employment allocated to services (ESE), (both $U R B$ and ESE were taken from the HDR database [35]).

The United Nations HDR [35] also provides data on the following three variables: 1) the number of physicians per 10,000 people $(P H Y) ; 2)$ a widely accepted country measure of gender inequality, the Gender Inequality Index (GII); and 3) the gross national income per capita $(Y P C)$, expressed in international dollars (PPP exchange rates) for comparability.

We used $P H Y$ and GII as proxy variables to account for country differences in the quality of health statistics registration and reporting [41], and the health, empowerment, and economic status of the female population, respectively. Indeed recent evidence suggests a significant direct relationship between the prevalence of overweight and obesity among women and the level of gender discrimination $[42,43]$. Income per capita $(Y P C)$ is included in our dataset as both a determinant of soft drink consumption and a key variable to compute soft drink affordability.

Finally, in the soft drink industry a few large international corporations control a highly globalized market [21], promoting changes in traditional dietary patterns and a convergence towards 'Western-style' eating habits [44-46]. These cultural and social transformations have been found in previous research to contribute to the rising obesity problem in lower- and middle-income countries [47]. We thus computed a basic country indicator of a 'Westernized lifestyle' to adjust our analysis for these potential confounding factors. This indicator, denoted WLS, is based upon the geometric mean of the KOF [48] Globalization Index (GLO) - a summary measure of a country's degree of economic, political, and social globalization - and the level of urbanization (URB).

Overall, all data refer to the years 2014 or 2015. A short description of each variable, along with basic descriptive statistics, is shown in Table 1 (for a full description and the complete database see Tables S1 and S2 in Additional file 1). The correlation coefficients, along with their statistical significance, are shown in Table 2.

\section{Methods}

Affordability refers to the quantity of resources, usually measured in terms of time or income, that a consumer 
Table 1 Descriptive statistics

\begin{tabular}{|c|c|c|c|c|c|c|}
\hline Variable & Description & Mean & Std. dev. & Min & Max & $n$ \\
\hline POW & $\begin{array}{l}\text { Prevalence of overweight } \\
\text { age-stand. Rate, both sex (BMI } \geq 25 \text { ), person } 18+\end{array}$ & 47.52 & 16.75 & 15.50 & 78.10 & 181 \\
\hline $\mathrm{POB}$ & $\begin{array}{l}\text { Prevalence of obesity } \\
\text { age-stand. Rate, both sex (BMI } \geq 30 \text { ), person } 18+\end{array}$ & 18.79 & 9.88 & 2.60 & 43.40 & 181 \\
\hline Q & $\begin{array}{l}\text { Per capita consumption of sugar-sweetened } \\
\text { beverages (Litres/person/year) }\end{array}$ & 56.62 & 43.69 & 0.69 & 236.58 & 183 \\
\hline QW & $\begin{array}{l}\text { Per capita consumption of (bottled still } \\
\text { and carbonated) water (Litres/person/year) }\end{array}$ & 48.96 & 48.00 & 0.16 & 205.43 & 183 \\
\hline YPC & Gross national income per capita, PPP \$ & $17,005.28$ & $17,365.99$ & 587.47 & $78,162.32$ & 182 \\
\hline$P$ & $\begin{array}{l}\text { (Average) Price of sugar-sweetened beverages } \\
\text { (PPP \$ per litre) }\end{array}$ & 3.17 & 1.08 & 0.78 & 6.79 & 154 \\
\hline SBA & $\begin{array}{l}\text { Sugar-sweetened beverage affordability } \\
\text { (SSB relative income price), (per 100 I, \%) }\end{array}$ & 6.21 & 8.76 & 0.36 & 42.54 & 154 \\
\hline PW & $\begin{array}{l}\text { (Average) Price of water } \\
\text { (bottled still and carbonated), (PPP \$ per litre) }\end{array}$ & 1.70 & 0.88 & 0.56 & 8.05 & 151 \\
\hline DES & Dietary energy supply (Kcal/person/day) & 2881.96 & 444.89 & 1937.00 & 3810.00 & 158 \\
\hline PHY & Number of physicians (per 10,000 people) & 16.06 & 14.83 & 0.14 & 67.23 & 177 \\
\hline GLO & KOF Globalization index & 58.48 & 16.44 & 23.98 & 92.84 & 178 \\
\hline URB & $\begin{array}{l}\text { Urban population } \\
\text { (\% of total population living in urban areas) }\end{array}$ & 56.57 & 23.22 & 8.45 & 100.00 & 182 \\
\hline Gll & UNDP Gender inequality index & 0.36 & 0.19 & 0.04 & 0.77 & 157 \\
\hline ESE & $\begin{array}{l}\text { Employment in services } \\
\text { (\% of total employment) }\end{array}$ & 54.21 & 17.61 & 16.20 & 85.70 & 182 \\
\hline WLS & Index of 'Western lifestyle' (GLO and URB) & 0.55 & 0.20 & 0.10 & 0.99 & 182 \\
\hline
\end{tabular}

needs to sacrifice to acquire a given amount of a specific good or service [31]. Following the current literature on the economics of alcohol [32, 49] and tobacco control [33], in this paper we measured the affordability of SSBs $(S B A)$ by the SSB 'relative income price'. This ratio indicates the percentage of the consumer's income-measured here by the gross national income per capita-required to buy 1001 of SSBs. In terms of our notation, $S B A=(100 P S D) / Y P C$. As a result, the higher the country's relative income price, the less affordable SSBs are in that country, and vice versa.

To explore the relationship between SSB affordability and the prevalence of overweight and obesity, the following multivariate regression models were developed. First, we investigated the impact of affordability $(S B A)$ on consumption $(Q)$. To this aim, we estimated two equations: 1) a standard demand function, including the average price of SSBs $(P)$ and the gross national income per capita $(Y P C)$ separately, along with the price of bottled water (as a related good, i.e. a substitute or a complement) and the 'Western lifestyle' index (WLS):

$$
Q_{i}=\beta_{0}+\beta_{1} P_{i}+\beta_{2} \ln Y P C_{i}+\beta_{3} P W_{i}+\beta_{4} W L S_{i}+\varepsilon_{i}
$$

and 2) a reformulation of the demand function, in which price and income are combined into the SSB 'relative income price' $(S B A)$, but $P W$ and $W L S$ maintain their role of demand shifters:

$$
Q_{i}=\beta_{0}+\beta_{1} \ln S B A_{i}+\beta_{2} P W_{i}+\beta_{3} W L S_{i}+\varepsilon_{i}
$$

(here and in the following equations, In stands for natural logarithm and the subscript $i$ denotes the $i$ th country).

Second, we isolated the impact of soft drink consumption on the population weight outcomes by regressing the age-standardized prevalence rate of overweight $(P O W)$ and that of obesity $(P O B)$ on the quantity of SSBs consumed per capita $(Q)$, after adjusting for the following main confounding factors: the amount of food available for human consumption (i.e. the dietary energy supply, $D E S)$, the percentage of employment in the service sector (ESE), the level of gender inequality (GII), and the number of physicians per 10,000 people $(P H Y)$ :

$$
\begin{aligned}
P O W_{i} & =\beta_{0}+\beta_{1} \ln Q_{i}+\beta_{2} \ln Q W_{i}+\beta_{3} \ln D E S_{i} \\
& +\beta_{4} \ln E S E_{i}+\beta_{5} \ln G I I_{i}+\beta_{6} \ln P H Y_{i}+\varepsilon_{i}
\end{aligned}
$$

Equation 3) is thus estimated twice, once with the prevalence of overweight $(P O W)$ and once with that of obesity $(P O B)$ as dependent variables (we denoted these 
Table 2 Correlation coefficients

\begin{tabular}{|c|c|c|c|c|c|c|c|c|c|c|c|c|c|}
\hline Variable & POW & $\mathrm{POB}$ & Q & QW & YPC & $P$ & SBA & PW & DES & $\mathrm{PHY}$ & GII & ESE & WLS \\
\hline POW & 1.000 & & & & & & & & & & & & \\
\hline POB & $.957^{* *}$ & 1.000 & & & & & & & & & & & \\
\hline Q & $.641^{* *}$ & $.572^{* *}$ & 1.000 & & & & & & & & & & \\
\hline QW & $.542^{* *}$ & $.526^{* *}$ & $.559^{* *}$ & 1.000 & & & & & & & & & \\
\hline YPC & $.496^{* *}$ & $.435^{* *}$ & $.716^{* *}$ & $.452^{* *}$ & 1.000 & & & & & & & & \\
\hline$P$ & $-.297^{* *}$ & $-.289^{* *}$ & $-.344^{* *}$ & -.144 & -.095 & 1.000 & & & & & & & \\
\hline SBA & $-.676^{* *}$ & $-.593^{* *}$ & $-.604^{* *}$ & $-.458^{* *}$ & $-.534^{* *}$ & $.285^{* *}$ & 1.000 & & & & & & \\
\hline PW & -.100 & -.116 & -.034 & -.193 & .026 & $.532^{* *}$ & .140 & 1.000 & & & & & \\
\hline DES & $.659^{* *}$ & $.602^{* *}$ & $.620^{* *}$ & $.515^{* *}$ & $.676^{* *}$ & $-.311^{* *}$ & $-.623^{* *}$ & $-.192^{*}$ & 1.000 & & & & \\
\hline PHY & $.567^{* *}$ & $.449^{* *}$ & $.590^{* *}$ & $.429^{* *}$ & $.610^{* *}$ & -.125 & $-.532^{* *}$ & -.043 & $.719^{* *}$ & 1.000 & & & \\
\hline GII & $-.538^{* *}$ & $-.416^{* *}$ & $-.667^{* *}$ & $-.419^{* *}$ & $-.751^{* *}$ & $.169^{*}$ & $.630^{* *}$ & .003 & $-.716^{* *}$ & $-.787^{* *}$ & 1.000 & & \\
\hline ESE & $.739^{* *}$ & $.676^{* *}$ & $.747^{* *}$ & $.490^{* *}$ & $.720^{* *}$ & $-.250^{* *}$ & $-.739^{* *}$ & .002 & $.718^{* *}$ & $.658^{* *}$ & $-.704^{* *}$ & 1.000 & \\
\hline WLS & $.567^{* *}$ & $.436^{* *}$ & $.697^{* *}$ & $.450^{* *}$ & $.669^{* *}$ & $-.164^{*}$ & $-.569^{* *}$ & -.004 & $.709^{* *}$ & $.714^{* *}$ & $-.728^{* *}$ & $.706^{* *}$ & 1.000 \\
\hline
\end{tabular}

eqs. $3 a$ and $3 b$, respectively). Finally, given that the consumption of bottled water $(Q W)$ should be unrelated to overweight and obesity, $Q W$ is used in eqs. $3 a$ and $3 b$ to check whether potentially relevant variables were omitted from the regression model $[28,29]$.

Third, the determinants of SSB consumption and those of the prevalence of overweight and obesity, taken from eqs. 2) and 3), were included as explanatory variables in a single model to measure the effect of SSB affordability on the prevalence rates of overweight and obesity, by holding all other confounding factors constant. In the case of overweight, we estimated the following regression equation:

$$
\begin{aligned}
P O W_{i} & =\beta_{0}+\beta_{1} \ln S B A_{i}+\beta_{2} \ln P W_{i}+\beta_{3} \ln D E S_{i} \\
& +\beta_{4} \ln E S E_{i}+\beta_{5} \ln G I_{i}+\beta_{6} \ln P H Y_{i}+\varepsilon_{i}
\end{aligned}
$$

Compared to eq. 2), this equation does not include the index of 'Western lifestyle' (WLS) to avoid problems of multicollinearity between regressors. Indeed, as shown in the last row of Table 2, the correlation coefficients between $W L S$ and the control variables DES, ESE, GII, and $P H Y$ are, on average, around $0.70(p<0.01)$. Again, by changing the dependent variable, we ran two versions of eq. 4), one for the prevalence of overweight ( $P O W$ ) and the other for that of obesity $(P O B)$, denoted respectively $4 a$ and $4 b$.

Finally, in all regression models, a semi-log specification was adopted where the relationship between independent and dependent variables was hypothesized to have an 'increasing at a decreasing rate' form, and White's corrected standard errors were chosen to adjust for heteroskedasticity [50].

\section{Results}

In Table 3 countries are clustered by their gross national income per capita, according to the World Bank income groups [51], to provide a first glimpse of SSB consumption, prices, and affordability worldwide. Overall, SSB consumption increased with the level of economic development, but it also showed great variability. In 2015, the average quantity consumed was approximately 61 and 1001 per capita in high- and upper-middle-income countries, respectively. The consumption in high-income countries, however, was approximately four and ten times higher than that observed in lower-middle and low-income countries (around 27 and 91 per capita, respectively). Data on the quantity consumed showed a very large dispersion even within groups, especially in lower-middle and low-income countries, where the coefficient of variation of consumption per capita was approximately $93 \%$ and $75 \%$, respectively.

Conversely, the average price of SSBs-corrected for purchasing power differences across countries-tended to decrease slightly with income per capita and showed less variability within groups than the quantity consumed. As can be seen in the second column of Table 3, the average price of SSBs in 2015 was approximately $\$ 3.5$ and $\$ 3.3$ per litre in low- and lower-middle-income countries, respectively. The price decreased to $\$ 3.2$ in upper-middle-income countries and dropped somewhat to $\$ 2.9$ per litre in high-income countries.

Given the large disparities in per capita income around the world, these figures about prices imply substantial cross-country differences in SSB affordability. Overall, affordability nearly tripled moving from low- to high-income countries. Specifically, in 2015, the fraction of gross national income per capita required to buy 1001 of SSBs was on average less than $1 \%$ (approximately $0.9 \%$ ) in high-income countries. This percentage increased to approximately $2.8 \%$ 
Table 3 Average SSB consumption, price and affordability, and the prevalence of overweight and obesity, by country income level (2015)

\begin{tabular}{|c|c|c|c|c|c|c|c|c|c|c|c|}
\hline \multirow[b]{4}{*}{ World Bank income group } & \multirow[b]{4}{*}{$n$} & \multirow{2}{*}{\multicolumn{2}{|c|}{$\frac{\mathrm{Q}}{\text { Consumption }}$}} & \multirow{2}{*}{\multicolumn{2}{|c|}{$\begin{array}{l}\mathrm{P} \\
\text { Price } \\
\end{array}$}} & \multirow{2}{*}{\multicolumn{2}{|c|}{$\begin{array}{l}\text { SBA } \\
\text { Affordability }\end{array}$}} & \multicolumn{2}{|l|}{ POW } & \multicolumn{2}{|l|}{$\mathrm{POB}$} \\
\hline & & & & & & & & Prevale & overweight & Prevale & obesity \\
\hline & & \multicolumn{2}{|c|}{ Litres/person/year } & \multicolumn{2}{|c|}{ PPP \$ per litre } & \multicolumn{2}{|c|}{$\%$ of GNI pc per 100 I } & \multicolumn{2}{|c|}{ Age std. rate, age $18+$} & \multicolumn{2}{|c|}{ Age std. rate, age $18+$} \\
\hline & & Mean & Std. dev. & Mean & Std. dev. & Mean & Std. dev. & Mean & Std. dev. & Mean & Std. dev. \\
\hline High-income, $\mathrm{HI}$ & 57 & 99.74 & 35.64 & 2.86 & 0.85 & 0.88 & 0.42 & 59.61 & 9.15 & 25.14 & 7.25 \\
\hline Upper-middle income, UMl & 53 & 60.73 & 26.74 & 3.23 & 1.20 & 2.77 & 1.32 & 54.46 & 10.74 & 22.79 & 7.12 \\
\hline Lower-middle income, LMI & 45 & 26.73 & 24.98 & 3.35 & 1.27 & 7.77 & 4.29 & 39.02 & 15.30 & 13.96 & 9.03 \\
\hline Low-income, LI & 28 & 9.09 & 6.91 & 3.47 & 0.81 & 24.58 & 9.59 & 24.28 & 5.06 & 6.50 & 2.42 \\
\hline
\end{tabular}

Note: World Bank country classifications by income level (GNI per capita in US \$, Atlas method): GNIpc <995= LI; $996 \leq$ GNIpc $\leq 3895=$ LMl; $3896 \leq$ GNIpc $\leq$ $12,055=\mathrm{UMI} ; \mathrm{GNIpc}>12,055=\mathrm{HI}$

in upper-middle-income countries. SSBs became less affordable especially in developing countries, where the fraction of income required to buy $100 \mathrm{l}$ rose sharply until reaching $7.7 \%$ and $24.6 \%$ in lower-middle and low-income countries, respectively. Here again, a remarkable variability between countries of the same income group was observed.

Table 4 contains a list of the top five countries for SSB consumption in 2015 for each of the six WHO geographic regions [52], along with the corresponding SSB affordability. It is notable that in the Americas, Europe, the Western Pacific regions, and in countries where SSBs were extremely affordable (i.e. the relative income price was, on average, approximately $0.5 \%$ ), the annual consumption per capita was often well above $100 \mathrm{l}$ (for instance, 167, 150, and 1441 in Mexico, Germany, and Japan, respectively). This implies an average daily consumption of around 0.3-0.4 l per inhabitant.

The nature of the association between SSB affordability $(S B A)$ and consumption $(Q)$ is better illustrated in Fig. 1, where $S B A$ and $Q$ are measured on the $\mathrm{x}$ and $\mathrm{y}$ axes, respectively. On the one hand, there was a clear inverse relationship between affordability and consumption $(r=-$ $0.62 ; p<0.01$, see Table 2). That is, increases in the 'relative income price' (i.e. a rightward movement along the $\mathrm{x}$-axis) lead to a decrease in the quantity consumed. On the other hand, despite greater affordability generally increasing the consumption of SSBs, around the same level of affordability (between $0.5 \%$ and $1.5 \%$ ) was associated with very different levels of consumption per capita. This was particularly the case for various countries in Europe and the Americas.

The impact of affordability on consumption was assessed in Table 5, which collects the regression results of eqs. 1) and 2). Despite its simplicity, this demand model was able to explain more than two-thirds of the variation in SSB consumption (the adjusted $R^{2}$ is approximately 0.7 in both specifications). Except for the price of bottled water, all estimated coefficients were statistically significant $(p<0.01)$ and had the predicted sign. Specifically, consumption increased with per capita income and 'Western lifestyle', whereas price and affordability were inversely related to quantity consumed.

What is most notable in these results, as shown by eq. 2 ), is that the consumption of SSBs, on average, fell by approximately 0.241 per capita for every $1 \%$ increase in the relative income price. Put differently, if affordability decreases by $10 \%$, the quantity consumed will drop by approximately 2.41 per capita, and vice versa. ${ }^{3}$

Figures 2 and 3 show the bivariate relationships between the age-standardized prevalence rate of obesity $(P O B)$ and, respectively, the consumption $(Q)$ and affordability $(S B A)$ of SSBs. In Fig. 2, the consumption of SSBs appears to be strongly and positively correlated with the prevalence of obesity ( $r=0.64 ; p<0.01$, see Table 2$)$, although the impact of consumption on obesity seems to increase at a decreasing rate. In Fig. 3, there is clear evidence that the prevalence of obesity decreases sharply as the relative income price of SSBs increases $(r=0.68 ; \mathrm{p}<0.01$, see Table 2$)$, especially in countries with values of $S B A$ higher than $1 \%$. Similar results can be found using the prevalence rate of overweight instead of that of obesity (as shown in Figures S1 and S2 in Additional file 1).

To further explore these relationships, Tables 6 and 7 present the results of the multivariate regression models expressed by eqs. 3) and 4). Specifically, Table 6 refers to the effects of SSB consumption and affordability on overweight (eqs. $3 a$ and $4 a$, respectively). In both equations, the goodness of fit was approximately 0.73 , which suggests that the models could explain a relatively large part of the variation in the prevalence of overweight, and all coefficients-except for the quantity and price of bottled water-were statistically significant at $1 \%$ (at $5 \%$ only in the case of dietary energy supply in eq. $4 a$ ). The analysis supports the hypothesis of a harmful impact of SSB affordability on the spread of overweight. After controlling for the effects of various potential confounding factors, these results show that every $10 \%$ increase in affordability (that is, every $10 \%$ decrease in the relative income price of SSBs) was associated, on average, with about 0.4 more overweight adults per 100 inhabitants. 
Table 4 SSB consumption and affordability: top five countries by geographic region (2015)

\begin{tabular}{|c|c|c|c|}
\hline & & Q & SBA \\
\hline & & Consumption & Affordability \\
\hline WHO Region & & (Litres/person/year) & (\% of GNI pc/100 I) \\
\hline Americas & United States & 236.58 & 0.36 \\
\hline & Mexico & 166.98 & 0.38 \\
\hline & Chile & 161.59 & 0.44 \\
\hline & Argentina & 157.40 & 0.47 \\
\hline & Canada & 154.54 & 0.48 \\
\hline Europe & Belgium & 155.73 & 0.70 \\
\hline & Germany & 150.65 & 0.49 \\
\hline & Switzerland & 143.41 & 0.54 \\
\hline & Norway & 134.79 & 0.55 \\
\hline & Netherlands & 129.16 & 0.55 \\
\hline Western Pacific & Japan & 144.27 & 0.53 \\
\hline & Australia & 131.07 & 0.55 \\
\hline & Hong Kong & 86.07 & 0.57 \\
\hline & New Zealand & 81.60 & 0.64 \\
\hline & Singapore & 76.32 & 0.49 \\
\hline South-East Asia & Thailand & 59.81 & 2.34 \\
\hline & Maldives & 37.86 & 2.42 \\
\hline & Indonesia & 20.23 & 1.07 \\
\hline & Sri Lanka & 10.74 & 3.07 \\
\hline & Myanmar & 5.21 & 11.47 \\
\hline Eastern Mediterranean & Saudi Arabia & 127.53 & 0.62 \\
\hline & Oman & 104.58 & 1.07 \\
\hline & Kuwait & 98.00 & 0.54 \\
\hline & United Arab Emirates & 97.88 & 0.67 \\
\hline & Bahrain & 95.43 & 1.00 \\
\hline Africa & South Africa & 103.24 & 2.15 \\
\hline & Botswana & 70.31 & 2.05 \\
\hline & Mauritius & 47.44 & 1.64 \\
\hline & Namibia & 46.91 & 3.69 \\
\hline & Algeria & 46.09 & 0.57 \\
\hline
\end{tabular}

Table 7 refers to the effects of SSB consumption and affordability on the prevalence of obesity (eqs. $3 b$ and $4 b$, respectively). Overall, the results are quite similar to those for overweight. There was a slight reduction in the coefficient of determination (the adjusted $R^{2}$ is around 0.67 ), and the number of physicians was not statistically significant in both equations. However, all other regressors (except quantity and price of bottled water) were statistically significant and again displayed the expected sign. The magnitude of the impact of affordability on obesity was approximately the same as that on overweight (approximately 0.38 more cases of obesity per 100 adults for each $10 \%$ increase in SSB affordability).
Finally, the regression analysis indicated that both the consumption and the price of bottled water were clearly unrelated to the prevalence of overweight and obesity. Although basic, this falsification test suggests that the observed harmful effects of SSB consumption and affordability on the population unhealthy weight outcomes were likely not due to some other omitted variables $[28,29]$.

\section{Discussion}

The present study was designed to determine the effect of SSB affordability on the prevalence of overweight and obesity by using cross-sectional country data. The analysis revealed three main findings. 


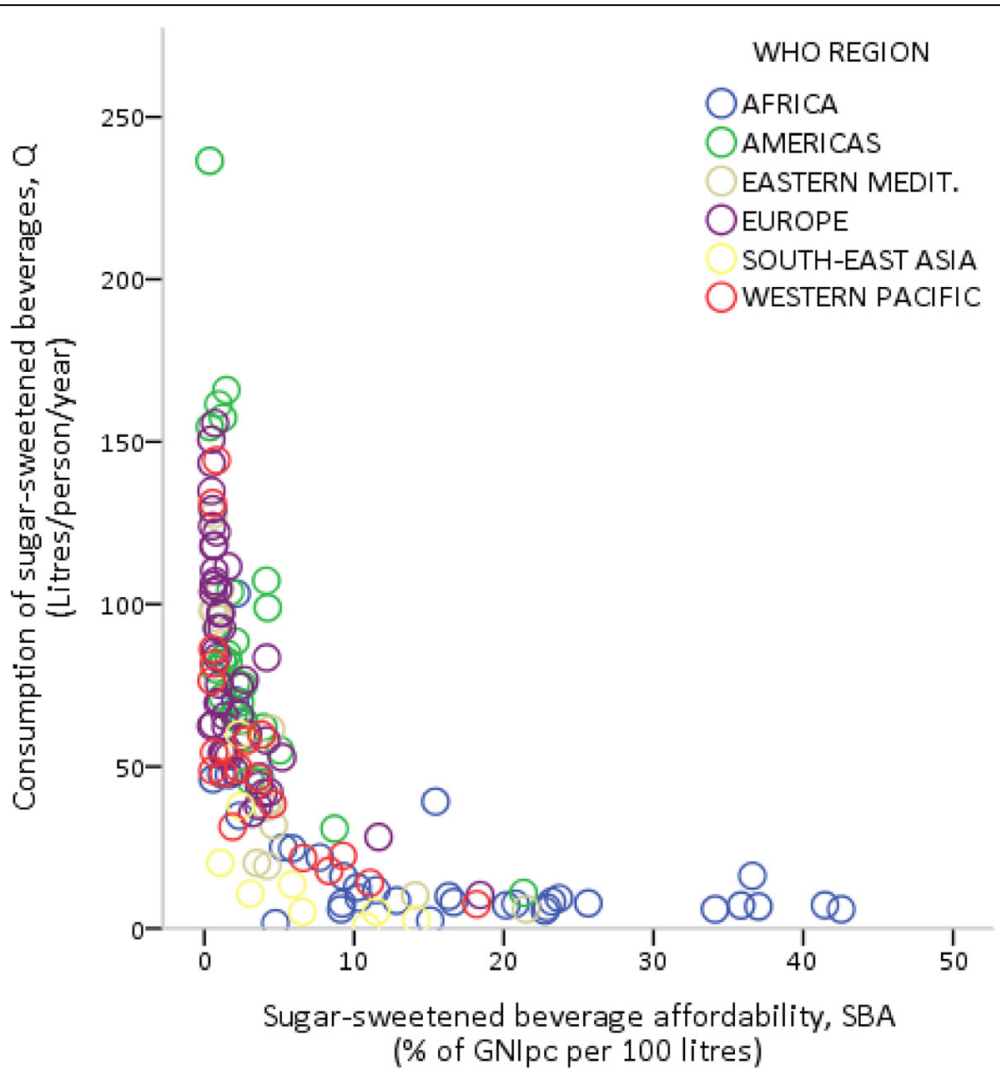

Fig. 1 Sugar-sweetened beverage affordability and consumption

First, the affordability of SSBs showed both a high variability across countries and a clear tendency to increase substantially with the level of economic development. Second, affordability played a key role in determining cross-country differences in the quantity of SSBs consumed per capita. Third, there was a significant inverse relationship between the relative income price of SSBs and the prevalence of overweight and obesity; that is, the age-standardized prevalence rates of overweight and obesity increased with increasing affordability, all other things being equal.

A number of important limitations need to be acknowledged when interpreting these results. First, the total sugar content of the world's most popular SSBs is

Table 5 Regression results: sugar-sweetened beverage demand function

\begin{tabular}{|c|c|c|c|c|}
\hline \multicolumn{5}{|c|}{ Dependent variable: sugar-sweetened beverage consumption per capita, Q } \\
\hline \multicolumn{2}{|l|}{ Equation (1) } & \multirow{2}{*}{$\begin{array}{l}\text { Coefficient } \\
-12.49^{*}\end{array}$} & \multirow{2}{*}{$\begin{array}{l}\text { Std. Error }{ }^{\mathrm{a}} \\
1.98\end{array}$} & \multirow{2}{*}{$\begin{array}{l}\text { t-statistic } \\
-6.30\end{array}$} \\
\hline (Average) Price of sugar-sweetened beverages & $\mathrm{P}$ & & & \\
\hline Gross national income per capita & $\ln (Y P C)$ & $21.93^{*}$ & 2.27 & 9.68 \\
\hline (Average) Price of water & PW & 3.32 & 2.89 & 1.15 \\
\hline Index of 'Western lifestyle' & WLS & $46.96^{*}$ & 13.48 & 3.48 \\
\hline \multicolumn{5}{|c|}{ Constant $=-135.23$, F-statistic $=86.67(p<0.01)$, Adj. R-squared $=0.71, n=150$} \\
\hline Equation (2) & & Coefficient & Std. Error ${ }^{a}$ & t-statistic \\
\hline Sugar-sweetened beverage affordability & $\ln (S B A)$ & $-24.11^{*}$ & 2.18 & -11.06 \\
\hline (Average) Price of water & PW & -0.69 & 2.97 & -0.23 \\
\hline Index of 'Western lifestyle' & WLS & $42.06^{*}$ & 12.52 & 3.36 \\
\hline \multicolumn{5}{|c|}{ Constant $=62.91$, F-statistic $=109.08(p<0.01)$, Adj. R-squared $=0.69, n=150$} \\
\hline
\end{tabular}

Notes: $\ln (\cdot)$ is natural log. ${ }^{*}$ Denote $p<0.01$

${ }^{a}$ White's heteroskedasticity-adjusted standard errors 


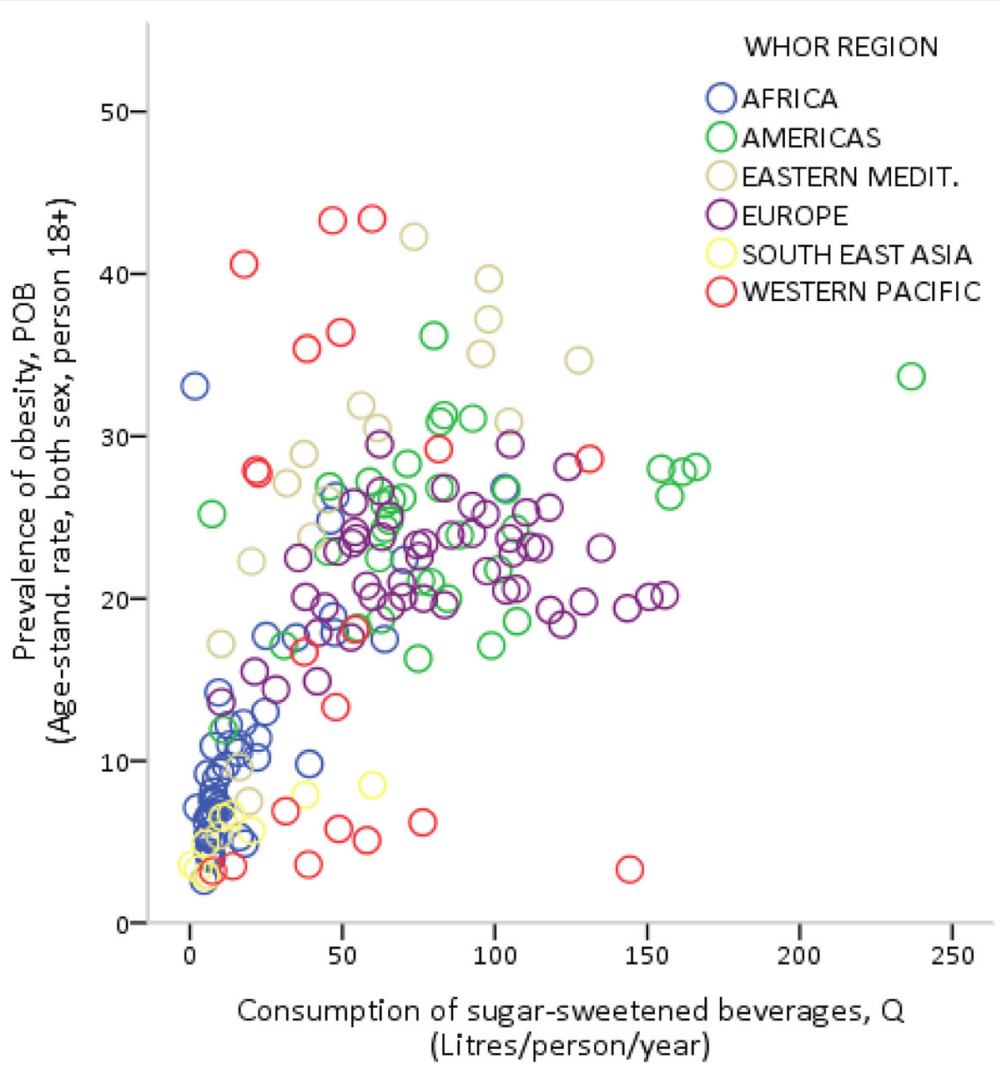

Fig. 2 Sugar-sweetened beverage consumption and the prevalence of obesity

on average approximately $10 \mathrm{~g}$ per $100 \mathrm{ml}$ [53]. However, there are significant differences among the different types of products available-for instance between regular and diet sodas-that our analysis, based on aggregate market data, failed to take into account. Second, we computed consumption per capita starting from total sales in volume, which includes different levels of waste, and thus tends to overestimate the effective quantity consumed in each country. Third, our consumption and prevalence data are not fully comparable, because they relate to the total and adult populations, respectively. This mismatch might lead to a underestimation of the impact of SSBs on the population weight outcomes. Fourth, the adverse effects of SSBs on overweight and obesity are linked to their regular consumption over a long period of time, a phenomenon that should be better examined using panel data [29]. Finally, one might think of unhealthy eating habits and weight outcomes as being determined, at least partially, simultaneously, and this would suggest the use of a simultaneous equation model to capture reciprocal causality, as well as the inclusion of the price of other unhealthy foods correlated with SSB consumption. Unfortunately, the lack of reliable data for our very large set of countries makes such investigations infeasible.
Despite these limitations, which are common to similar works [28], this study offers some useful insights for policymakers. In the context of the existing debate on how to curb the 'obesity epidemic' [54], our findings support current recommendations that fiscal policy should be included as part of a comprehensive strategy to prevent overweight and obesity [55]. This paper adds, as shown in Fig. 4, some empirical evidence that suggests the use of the affordability of SSBs, rather than just the price of SSBs, as an 'intermediate target' for health-related policies.

Figure 4 shows that the market conditions (i.e. price elasticities) and the firm's pricing strategies determine how much of the excise tax is 'passed through' to consumers in a higher retail market price. Shelf price and the consumers' disposable income, in turn, determine the level of affordability (i.e. the relative income price of SSBs). Finally, affordability and consumers' tastes determine the purchasing behaviour and thus the quantity consumed.

The economic rationale behind the current choice to use excise taxes as a tool to control consumption lies in the price elasticity of the demand for these beverages that, despite some variability among studies, is frequently estimated [56] to be approximately $1 \%$ or even higher (for instance, on average, $1.2 \%$ in the United States, France, Brazil, and Mexico [57]). 


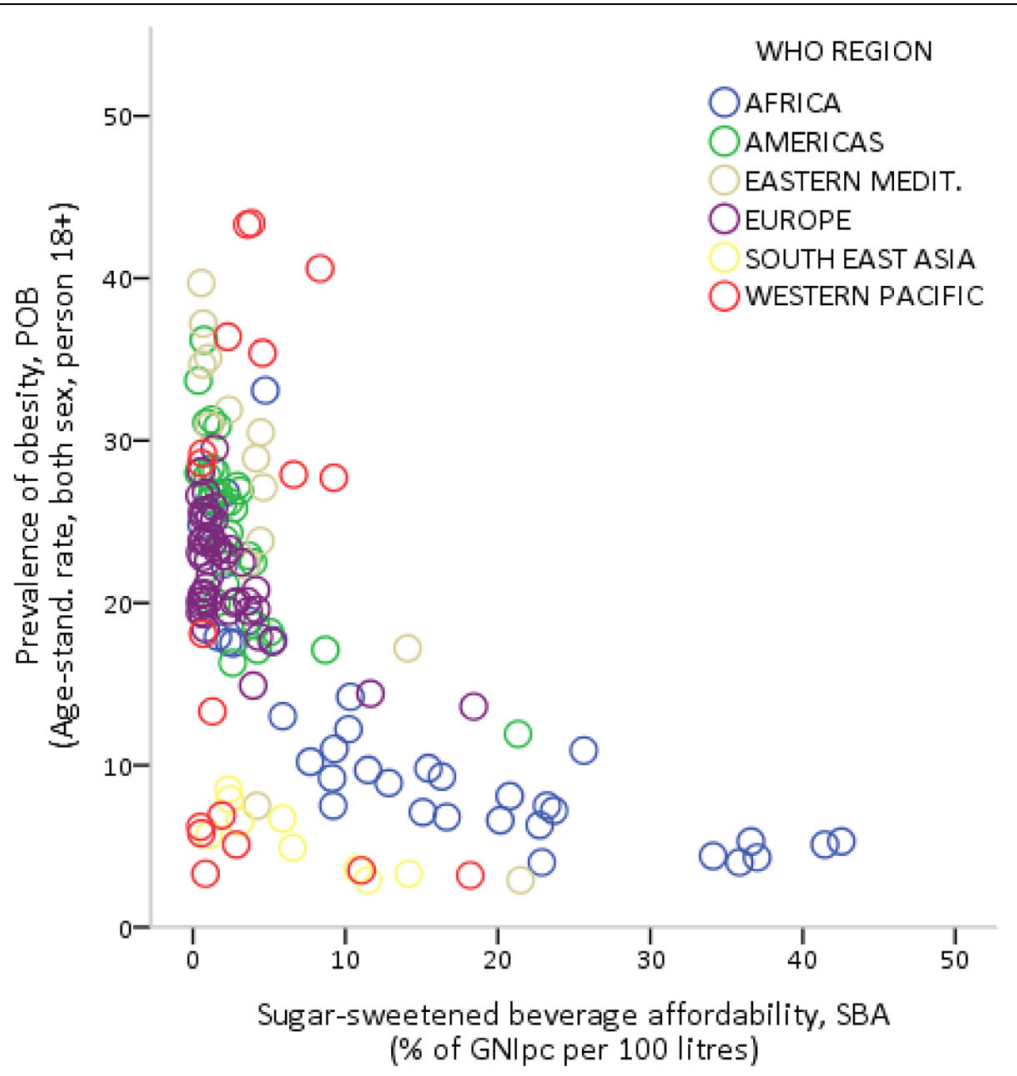

Fig. 3 Sugar-sweetened beverage affordability and the prevalence of obesity

Table 6 Regression results: sugar-sweetened beverage consumption, affordability and overweight

Dependent variable: prevalence of overweight, POW

Equation (3a)

Per capita consumption of sugar-sweetened beverages

Per capita consumption of water

Dietary energy supply

Employment in services

Gender inequality index

Number of physicians

Constant $=-188.42$, F-statistic $=65.61(p<0.01)$, Adj.

R-squared $=0.73, n=144$

Equation (4a)

Sugar-sweetened beverage affordability

(Average) Price of water

Dietary energy supply

Employment in services

Gender inequality index

Number of physicians
$\operatorname{Ln}(\cdot)$

Q

QW

DES

ESE

GII

$\mathrm{PHY}$

$\operatorname{Ln}(\cdot)$

SBA

PW

DES

ESE

GII

PHY
Coefficient

$5.42^{* *}$

0.61

$20.26^{* *}$

$13.92^{* *}$

$5.53^{* *}$

$2.20^{* *}$

Coefficient

$-4.09 * *$

0.29

$16.21^{*}$

$15.15^{* *}$

$5.29^{* *}$

$2.95^{* *}$
Std. Error ${ }^{a}$

1.31

1.04

7.06

3.64

1.35

0.79

Std. Error ${ }^{a}$

1.51

2.03

6.70

4.52

1.33

0.83 t-statistic

4.13

0.59

2.87

3.82

4.08

2.79

Constant $=-135.84$, F-statistic $=54.72(p<0.01)$, Adj. R-squared $=0.73, n=120$ 
Table 7 Regression results: sugar-sweetened beverage consumption, affordability and obesity

Dependent variable: prevalence of obesity, POB

Equation (3b)

$\operatorname{Ln}(\cdot)$

Per capita consumption of sugar-sweetened beverages

Per capita consumption of water

Dietary energy supply

Employment in services

Gender inequality index

Number of physicians

Constant $=146.91$, F-statistic $=48.35(p<0.01)$, Adj.

R-squared $=0.67, n=144$

Equation (4b)

Sugar-sweetened beverage affordability

(Average) Price of water

Dietary energy supply

Employment in services

Gender inequality index

Number of physicians

Constant $=-93.43$, F-statistic $=38.70(p<0.01)$, Adj. R-squared $=0.66, n=120$

$=120$

Notes: $\ln (\cdot)$ is natural log. ${ }^{*}$ and ${ }^{* *}$ denote $p<0.01$ and $p<0.05$, respectively

a'White's heteroskedasticity-adjusted standard errors

$\begin{array}{llll}\text { Q } & 3.27^{* *} & 0.77 & 4.27 \\ \text { QW } & 0.34 & 0.64 & 0.52 \\ \text { DES } & 15.27^{* *} & 4.11 & 3.71 \\ \text { ESE } & 8.91^{* *} & 2.35 & 3.80 \\ \text { GII } & 4.68^{* *} & 0.91 & 5.16 \\ \text { PHY } & 0.61 & 0.49 & 1.24\end{array}$

$\begin{array}{llll}\text { Ln(.) } & \text { Coefficient } & \text { Std. Error } & \text { t-statistic } \\ \text { SBA } & -3.81^{* *} & 1.07 & -3.57 \\ \text { PW } & 0.70 & 1.37 & 0.51 \\ \text { DES } & 10.83^{* *} & 4.00 & 2.71 \\ \text { ESE } & 8.93^{*} & 3.45 & 2.59 \\ \text { GII } & 5.21^{* *} & 0.98 & 5.32 \\ \text { PHY } & 0.60 & 0.54 & 1.11\end{array}$


The fiscal approach, however, is based upon a static demand model, in which an increase in price, due to an excise tax, leads to a decrease in the quantity demanded; (that is, a movement along a given demand curve, where the consumers' income and tastes remain unchanged). Instead, research has consistently shown that a key contributor to the obesity epidemic is that of structural changes in dietary patterns-i.e. the shift from traditional to Western-style diets-that result from the dynamic effects of rising income on consumers' tastes and preferences in evolving technical and social environments [58].

Especially in growing economies, besides the question of how much of the tax burden falls on buyers as a higher retail price, relatively small changes in the nominal price of SSBs might be easily offset in the long-term by aggressive marketing strategies (e.g. indirect price discrimination through quantity discounts) and rising disposable income [59].

\section{Conclusions}

By using Coca-Cola as a proxy for all SSBs, a recent study found that, during the last decades, SSBs have become more affordable around the world and especially in developing countries [30]. In this paper, we collected the latest statistics available on the beverage industry to compute SSB affordability for approximately 150 countries worldwide. These data were used to assess the impact of affordability-as measured by the SSB relative income price-on the prevalence of overweight and obesity. Our results clearly indicate that affordability: 1) is a major driver of purchasing behaviours, and 2) is significantly associated with the prevalence rates of both overweight and obesity.

This association obviously does not imply a causal relationship, and the use of country data offers the potential for ecological fallacies. However, soft drink affordability emerged as a reliable predictor of weight outcomes even after correcting for the main potential confounding factors. These results enhance our understanding of the harmful effects of SSBs and support the use of fiscal tools to control their consumption, by stressing the importance to focus on the effects of 'soda taxes' on the SSB relative income price ${ }^{\mathrm{d} .4}$ However, there are still many intriguing issues which should be explored in further research, particularly to explain why in high-income countries very similar social and economic structures are associated with widely varying levels of SSB consumption.

\section{Endnotes}

${ }^{1}$ The British Medical Association defines SSBs as all non-alcoholic water based beverages with added sugar, including sugar-sweetened soft drinks, energy drinks, fruit drinks, sports drinks and fruit juice concentrates [18].
${ }^{2}$ Asian soft drinks are traditional or national (carbonated and non-carbonated) SSBs commonly found in several Western Pacific and Southern-East Asian countries (especially, in Japan, Malaysia, Indonesia, Thailand and the Philippines), such as ready-to-drink tea, cereal-pulse or milk based specialties, and many different type of local fruit-flavoured soda [20].

${ }^{3}$ By using affordability in the demand function as an interactive term, we obtained the following results:1) $\mathrm{Q}=43.74-11.41 \mathrm{P}+0.0009 \mathrm{YPC}-9398.35(\mathrm{P} / \mathrm{YPC})+3.4$ $4 \mathrm{PW}+63.49 \mathrm{WLS}(2.19)(0.0003)(2467.32)(3.10)(17.73) \mathrm{t}$ $\left.=-5.203 .34-3.81 \quad 1.113 .58 \mathrm{Adj} . \mathrm{R}^{2}=0.68, n=1502\right)$ $\mathrm{Q}=12.21-4.19 \mathrm{P}+0.003 \mathrm{YPC}-0.0005(\mathrm{P} * \mathrm{YPC})+1.65$ $\mathrm{PW}+$ 59.98WLS(2.62) (0.0006) (0.0001) (2.97) (17.45)t = 1.60 4.61-3.38 0.56 3.44Adj. $\mathrm{R}^{2}=0.66, n=150$.Where White's heteroskedasticity-adjusted standard errors are given parentheses. In each equation, the coefficient of the interactive term is significant at the $1 \%$ level. These results further support the use of the concept of affordability to investigate the consumption of SSBs.

${ }^{4}$ It should be noted that, especially in high income countries, the major players in the beverage industry are currently trying to respond to public health concerns by replacing sugar (including high fructose corn syrup) with different types of artificial sweeteners [20]. From the perspective of public health, however, this marketing strategy could simply replace one problem with another, because of the potential harmful effects of these chemical additives on human health [60].

\section{Additional file}

Additional file 1: Including the following Tables and Figures: Table S1. Source and short description of each variable. Table S2. Raw data (full dataset, with 183 countries). Figure S1. Sugar-sweetened beverage consumption and the prevalence of overweight. Figure S2. Sugar-

sweetened beverage affordability and the prevalence of overweight. (XLS $173 \mathrm{~kb})$

\section{Acknowledgements}

The authors would like to thank three anonymous reviewers for their suggestions and careful reading that helped improve the manuscript.

\section{Funding}

This research received no specific grant from any funding agency in the public, commercial, or not-for-profit sectors.

Availability of data and materials

All data generated or analyzed during this study are included in this published article and its supplementary information files.

\section{Authors' contributions}

FF: conceived and designed the study, collected the data, performed the experiments, analysed and interpreted the results, and wrote the paper. MM: analysed and interpreted the results and wrote the paper. Both authors read and approved the final manuscript.

Ethics approval and consent to participate Not applicable. 


\section{Consent for publication}

Not applicable.

\section{Competing interests}

The authors declare that they have no competing interests.

\section{Publisher's Note}

Springer Nature remains neutral with regard to jurisdictional claims in published maps and institutional affiliations.

\section{Received: 12 December 2018 Accepted: 3 April 2019} Published online: 18 April 2019

\section{References}

1. World Health Organization. Obesity and overweight. Fact sheet. February 2018. http://www.who.int/news-room/fact-sheets/detail/obesity-andoverweight. Accessed 12 Oct 2018.

2. Centers for Disease Control and Prevention. The health effects of overweight and obesity. May 2015. https://www.cdc.gov/healthyweight/ effects/index.html. Accessed 12 Oct 2018.

3. World Health Organization. Global strategy on diet, physical activity and health. Geneva: World Health Organization; 2004

4. Kumanyika SK, Parker L, Sim L, editors. Bridging the evidence gap in obesity prevention. Washington (DC): National Academies Press (US); 2010 https://doi.org/10.17226/12847

5. Ng M, Fleming T, Robinson M, Thomson B, Graetz N, et al. Global, regional, and national prevalence of overweight and obesity in children and adults during 1980-2013: a systematic analysis for the global burden of disease study 2013. Lancet. 2014;384(9945):766-81 https://doi.org/10.1016/s01406736(14)60460-8.

6. World Health Organization. Overweight and obesity: Global health observatory data. August 2018. http://www.who.int/gho/ncd/risk_factors/ overweight text/en/. Accessed 15 Oct 2018.

7. Kelly T, Yang W, Chen C-S, Reynolds K, He J. Global burden of obesity in 2005 and projections to 2030. Int J Obes. 2008:32(9):1431-7 https://doi.org/ 10.1038/ijo.2008.102.

8. Hall KD, Heymsfield SB, Kemnitz JW, Klein S, Schoeller DA, et al. Energy balance and its components: implications for body weight regulation. Am J Clin Nutr. 2012;95(4):989-94 https://doi.org/10.3945/ajcn.112.036350.

9. Romieu I, Dossus L, Barquera S, Blottière HM, Franks PW, et al. Energy balance and obesity: what are the main drivers? Cancer Causes Control. 2017;28(3):247-58. https://doi.org/10.1007/s10552-017-0869-z.

10. Hruby A, Hu FB. The epidemiology of obesity: a big picture. PharmacoEconomics. 2015;33(7):673-89. https://doi.org/10.1007/s40273-014-0243-x.

11. Swinburn B, Egger G, Raza F. Dissecting obesogenic environments: the development and application of a framework for identifying and prioritizing environmental interventions for obesity. Prev Med. 1999;29(6):563-70 https://doi.org/10.1006/pmed.1999.0585.

12. Townshend T, Lake A. Obesogenic environments: current evidence of the built and food environments. Perspectives in Public Health. 2017;137(1):3844 https://doi.org/10.1177/1757913916679860.

13. Cawley J, editor. The Oxford handbook of the social science of obesity. Oxford: Oxford University Press; 2011. https://doi.org/10.1093/oxfordhb/ 9780199736362.001.0001

14. Monteiro CA, Moubarac J-C, Cannon G, Ng SW, Popkin B. Ultra-processed products are becoming dominant in the global food system. Obes Rev. 2013;14:21-8 https://doi.org/10.1111/obr.12107.

15. Martínez Steele E, Baraldi LG, Louzada ML, Moubarac JC, Mozaffarian D, et al. Ultra-processed foods and added sugars in the US diet: evidence from a nationally representative cross-sectional study. BMJ Open. 2016;6(3):e009892 https://doi.org/10.1136/bmjopen-2015-009892.

16. Monteiro CA, Moubarac J-C, Levy RB, Canella DS, Louzada MLDC, et al. Household availability of ultra-processed foods and obesity in nineteen European countries. Public Health Nutr. 2017;21(01):18-26 https://doi.org/10. 1017/s1368980017001379.

17. Pan American Health Organization. Ultra-processed food and drink products in Latin America: trends, impact on obesity, policy implications. Washington, DC: Pan American Health Organization; 2004.

18. British Medical Association. Food for thought: promoting healthy diets among children and young people. London: British Medical Association Board of Science; 2015
19. The National Policy \& Legal Analysis Network to Prevent Childhood Obesity. Breaking down the chain: a guide to the soft drink industry. Newark: ChangeLab Solution; 2012.

20. Kleiman S, Ng SW, Popkin B. Drinking to our health: can beverage companies cut calories while maintaining profits? Obes Rev. 2011;13(3):25874 https://doi.org/10.1111/j.1467-789x.2011.00949.x.

21. Moodie R, Stuckler D, Monteiro C, Sheron N, Neal B, et al. Profits and pandemics: prevention of harmful effects of tobacco, alcohol, and ultraprocessed food and drink industries. Lancet. 2013;381(9867):670-9 https:// doi.org/10.1016/s0140-6736(12)62089-3.

22. Euromonitor. Passport: soft drinks industry overview. London: Euromonitor International; 2018.

23. Hu FB. Resolved: there is sufficient scientific evidence that decreasing sugarsweetened beverage consumption will reduce the prevalence of obesity and obesity-related diseases. Obes Rev. 2013;14(8):606-19 https://doi.org/10. 1111/obr.12040.

24. Deshpande G, Mapanga RF, Essop MF. Frequent sugar-sweetened beverage consumption and the onset of cardio-metabolic diseases: cause for concern? Journal of the Endocrine Society. 2017;1(11):1372-85 https://doi. org/10.1210/js.2017-00262.

25. Imamura F, O'Connor L, Ye Z, Mursu J, Hayashino Y, et al. Consumption of sugar sweetened beverages, artificially sweetened beverages, and fruit juice and incidence of type 2 diabetes: systematic review, meta-analysis, and estimation of population attributable fraction. BMJ. 2015;21:h3576 https:// doi.org/10.1136/bmj.h3576.

26. Frieden TR. Six components necessary for effective public health program implementation. Am J Public Health. 2014;104(1):17-22 https://doi.org/10. 2105/ajph.2013.301608.

27. Lee A, Mhurchu CN, Sacks G,Swinburn B, Snowdon W, Vandevijvere S, et al. Monitoring the price and affordability of foods and diets globally. Obesity Reviews. 2013;17(14):82-95. https://doi.org/10.1111/obr.12078.

28. Basu S, McKee M, Galea G, Stuckler D. Relationship of soft drink consumption to global overweight, obesity, and diabetes: a cross-national analysis of 75 countries. Am J Public Health. 2013;103(11):2071-7 https://doi. org/10.2105/ajph.2012.300974.

29. Goryakin Y, Monsivais $P$, Suhrcke M. Soft drink prices, sales, body mass index and diabetes: evidence from a panel of low-, middle- and high-income countries. Food Policy. 2017;73:88-94 https://doi.org/10.1016/j.foodpol.2017. 09.002.

30. Blecher E, Liber AC, Drope JM, Nguyen B, Stoklosa M. Global trends in the affordability of sugar-sweetened beverages, 1990-2016. Preventing Chronic Disease. Centers for Disease Control and Prevention; 2017 May 4;14. https:// doi.org/10.5888/pcd14.160406

31. Blecher EH, van Walbeek CP. Cigarette affordability trends: an update and some methodological comments. Tobacco Control BMJ. 2009;18(3):167-75 https://doi.org/10.1136/tc.2008.026682.

32. Rabinovich L, Brutscher PB, de Vries H, Tiessen J, Clift J, et al. The affordability of alcoholic beverages in the European Union: understanding the link between alcohol affordability, consumption and harms. Cambridge UK: Rand Europe and European Commission; 2009.

33. Blecher $\mathrm{EH}$. An international analysis of cigarette affordability. Tobacco Control BMJ. 2004;13(4):339-46 https://doi.org/10.1136/tc.2003.006726.

34. Euromonitor. Passport: Global market information database. http://www. portal.euromonitor.com/portal. March 2018. Accessed 12 Oct 2018.

35. United Nations Development Programme. Human Development Reports Database. http://hdr.undp.org/en/content/database. Accessed 12 Oct 2018.

36. World Bank. PPP conversion factors. International comparison program database. World Development Indicators. https://data.worldbank.org/ indicator/pa.nus.ppp. Accessed 12 Oct 2018.

37. World Health Organization. Global Health Observatory data repository: overweight and obesity. http://apps.who.int/gho/data/node.main. A897A?lang=en. September 2017. Accessed 12 October 2018.

38. Vandevijvere S, Chow CC, Hall KD, Umali E, Swinburn BA. Increased food energy supply as a major driver of the obesity epidemic: a global analysis. Bull World Health Organ. 2015;93(7):446-56 https://doi.org/10.2471/blt.14.150565.

39. Food and Agriculture Organization. Food and nutrition in numbers. Rome: Food and Agriculture Organization; 2014.

40. Goryakin Y, Suhrcke M. Economic development, urbanization, technological change and overweight: what do we learn from 244 demographic and health surveys? Economics \& Human Biology. 2014;14:109-27 https://doi. org/10.1016/j.ehb.2013.11.003. 
41. Mondal MNI, Shitan M. Relative importance of demographic, socioeconomic and health factors on life expectancy in low- and lower-middle-income countries. Journal of Epidemiology. 2014;24(2):117-24 https://doi.org/10. 2188/jea.je20130059.

42. Garawi F, Devries K, Thorogood N, Uauy R. Global differences between women and men in the prevalence of obesity: is there an association with gender inequality? Eur J Clin Nutr. 2014;68(10):1101-6 https://doi.org/10. 1038/ejcn.2014.86.

43. Ferretti F, Mariani M. Gender discrimination, gender disparities in obesity and human development. Heliyon. 2017;3(3):e00263 https://doi.org/10.1016/ j.heliyon.2017.e00263.

44. Alexander E, Yach D, Mensah GA. Major multinational food and beverage companies and informal sector contributions to global food consumption: implications for nutrition policy. Glob Health. 2011;7(1):26 https://doi.org/10. 1186/1744-8603-7-26.

45. Baker P, Friel S, Schram A, Labonte R. Trade and investment liberalization, food systems change and highly processed food consumption: a natural experiment contrasting the soft-drink markets of Peru and Bolivia. Globalization and Health. 2016;12(1) https://doi.org/10.1186/s12992-016-0161-0.

46. Lin TK, Teymourian Y, Tursini MS. The effect of sugar and processed food imports on the prevalence of overweight and obesity in 172 countries. Globalization and Health. 2018;14(1) https://doi.org/10.1186/s12992-018-0344-y.

47. Goryakin Y, Lobstein T, James WPT, Suhrcke M. The impact of economic, political and social globalization on overweight and obesity in the 56 low and middle income countries. Soc Sci Med. 2015;133:67-76 https://doi.org/ 10.1016/j.socscimed.2015.03.030.

48. Savina G, Haelg F, Sturm JE. The KOF globalisation index - revisited, KOF working paper, no. 439. The KOF Swiss Economic Institute: Zurich; 2018.

49. Burton R, Henn C, Lavoie D, O'Connor R, Perkins C, et al. A rapid evidence review of the effectiveness and cost-effectiveness of alcohol control policies: an English perspective. Lancet. 2017;389(10078):1558-80 https://doi. org/10.1016/s0140-6736(16)32420-5.

50. Studenmund AH. Using econometrica. A practical guide. New York: Pearson; 2015.

51. The World Bank. New country classifications by income level: 2018-2019. https://blogs.worldbank.org/opendata/new-country-classifications-incomelevel-2018-2019. Accessed 12 Oct 2018.

52. World Health Organization. Definition of regional groupings. https://www. who.int/choice/demography/by_country/en/. Accessed 12 Oct 2018.

53. Ventura EE, Davis JN, Goran MI. Sugar content of popular sweetened beverages based on objective laboratory analysis: focus on fructose content. Obesity. 2010;19(4):868-74 https://doi.org/10.1038/oby.2010.255.

54. Livingston EH. Reimagining obesity in 2018. JAMA. 2018;319(3):238 https:// doi.org/10.1001/jama.2017.21779.

55. World Health Organization. Using price policies to promote healthier diets http://www.euro.who.int/_data/assets/pdf_file/0008/273662/Using-pricepolicies-to-promote-healthier-diets.pdf. Accessed October 19, 2017.

56. Powell LM, Maciejewski ML. Taxes and sugar-sweetened beverages. JAMA. 2018;319(3):229 https://doi.org/10.1001/jama.2017.19522.

57. Cabrera Escobar MA, Veerman JL, Tollman SM, Bertram MY, Hofman KJ. Evidence that a tax on sugar sweetened beverages reduces the obesity rate: a meta-analysis. BMC Public Health. 2013;13(1) https://doi.org/10.1186/ 1471-2458-13-1072.

58. Popkin BM, Adair LS, Ng SW. Global nutrition transition and the pandemic of obesity in developing countries. Nutr Rev. 2012;70(1):3-21 https://doi.org/ 10.1111/j.1753-4887.2011.00456.x.

59. Lin B-H, Smith TA, Lee J-Y, Hall KD. Measuring weight outcomes for obesity intervention strategies: the case of a sugar-sweetened beverage tax. Economics \& Human Biology. 2011;9(4):329-41 https://doi.org/10.1016/j.ehb. 2011.08.007

60. Gardner C, Wylie-Rosett J, Gidding SS, Steffen LM, Johnson RK, et al. Nonnutritive sweeteners: current use and health perspectives. Circulation. 2012; 126(4):509-19 https://doi.org/10.1161/cir.0b013e31825c42ee.

Ready to submit your research? Choose BMC and benefit from:

- fast, convenient online submission

- thorough peer review by experienced researchers in your field

- rapid publication on acceptance

- support for research data, including large and complex data types

- gold Open Access which fosters wider collaboration and increased citations

- maximum visibility for your research: over $100 \mathrm{M}$ website views per year

At BMC, research is always in progress.

Learn more biomedcentral.com/submissions 